\title{
GMR
}

\section{Analysis of polymorphisms in the FUT1 and TAP1 genes and their influence on immune performance in Pudong White pigs}

\author{
Y. Zhang', M. Wang', X.Q. Yu², C.R. Ye' and J.G. Zhu' ${ }^{1}$ \\ 1Shanghai Key Laboratory of Veterinary Biological Technology, \\ School of Agriculture and Biology, Shanghai JiaoTong University, \\ Shanghai, China \\ 2Preventive Veterinary Center of Pudong District, Shanghai, \\ South Chuanhuan, Shanghai, China \\ Corresponding author: J.G. Zhu \\ E-mail: zhu_jg@sjtu.edu.cn \\ Genet. Mol. Res. 14 (4): 17193-17203 (2015) \\ Received August 10, 2015 \\ Accepted October 1, 2015 \\ Published December 16, 2015 \\ DOI http://dx.doi.org/10.4238/2015.December.16.19
}

\begin{abstract}
FUT1 and TAP1 have been identified as candidate genes that offer resistance against Escherichia coli F18 infection, with the AA genotype in FUT1 and the GG genotype in TAP1 conferring resistance. In order to confirm polymorphisms at FUT1 M307 and TAP1 G729, and evaluate their influence on immunity performance in Pudong White pigs, we performed polymerase chain reaction-restriction fragment length polymorphism analysis, measured immune indices, and compared the results with those observed in Large White pigs. The AA genotype of FUT1 was first discovered in Pudong White pigs and has not been found in other Chinese domestic pig breeds. The frequency of the AA genotype in Pudong White and Large White pigs was 0.018 and 0.052 , respectively. The GG genotype of TAP1 was also detected in the two breeds, with a frequency of 0.708 and 0.695 , respectively. Chi-square fitness analysis of both genes showed that these loci deviated from Hardy-Weinberg equilibrium in the two breeds $(P<0.05)$. No significant differences were observed in
\end{abstract}


interleukin-6 (IL-6) and IL-10 levels among the three genotypes at FUT1 and TAP1 in the two breeds $(P>0.05)$. Individuals for all genotypes of TAP1 in both pig breeds had similar TNF- $\alpha$ levels $(P>0.05)$, implying that Pudong White pigs may have the same ability for hepatocyte inflammatory response and $B$ cell differentiation as Large White pigs. These differences have a degree of influence on Pudong White pig's immune ability to resist F18 or other infections.

Key words: FUT1; TAP1; Disease resistance; Pudong White pig; Immune indexes; Polymorphism

\section{INTRODUCTION}

Edema disease (ED) and post-weaning diarrhea (PWD) are the most frequent, acute, and fatal transmitted diseases in piglets and they are caused by enterotoxigenic Escherichia coli (ETEC). In piglets at 4 to 12 weeks of age, incidence of these diseases is 30 to $40 \%$, with $40 \%$, and in some cases up to $90 \%$, mortality (Imberechts et al., 1992). Pathogenicity of ECF18 (Enterotoxigenic Escherichia coli F18) bacteria depends on the existence of the F18 receptor (Benin and DuchetSuchaux, 1991). The ETEC F18 pathogen adheres to the surface of epithelial cells of the small intestines of piglets via its fimbriae, and it binds to F18 receptors in the brush border membrane of epithelial cells in the intestinal mucosa, which results in colonization, replication, and enterotoxin production, leading to diseases in piglets (Bertin and Duchet-Suchaux, 1991; Nagy and Fekete, 1999). Vogeli et al. (1997) reported that the alpha(1,2) fucosyltransferase 1 gene (FUT1) controls the adhesion of ETEC F18. Meijerink et al. (1997) showed that when the M307 G/A mutation occurs in the FUT1 gene, swine with the AA genotype have a better ability to resist ETEC F18 infection, whereas AG or GG genotypes are sensitive to $\mathrm{F} 18$ infection. These results confirmed that breeding for disease resistance could be implemented by marker-assisted selection using FUT1 as the ETEC F18R candidate gene (Meijerink et al., 1997).

Transporter associated with antigen processing (TAP) is a protein transporter that consists of TAP1 and TAP2 proteins and belongs to the ATP-binding cassette family of transporters. As an integral membrane protein, TAP1 plays an important role in providing numerous candidate peptides to the major histocompatibility complex class I (MHC I) molecules within the peptide loading complex (Parcej and Tampe, 2010). The function of TAP1 is to transport peptides generated by proteasomal degradation to the endoplasmic reticulum lumen, after which they are transported to the cell surface to be combined with MHC class I molecules, where cluster of differentiation 8 (CD8)+ T cells and NK cells (Natural Killer Cells) settle them with specific recognition and processing, after which the target cell is lysed and the virus is killed (Cresswell et al., 1999). TAP is related to autoimmune disease and plays a significant role in immune responses because of its high expression level after infection by viruses and bacteria (Sun et al., 2012). Recently, some researchers have reported that TAP1 may be an effective anti-E. coli F18 molecular marker in pigs (Ambagala et al., 2003). Bao et al. (2012) detected genetic variations in exon 3 of the TAP1 gene and evaluated TAP1 mRNA expression levels among the different genotypes, and found the G729A mutation had a significant effect on mRNA expression of TAP1, with individuals with the GG genotype possessing a stronger ability to resist $E$. coli $\mathrm{F} 18$ infection.

The Pudong White pig is the only Chinese indigenous pig breed covered with full white hair. It is supported as a new Chinese local breed and has recently been added to the national 
livestock or poultry genetic resource protection list by the National Ministry of Agriculture in China. As there are fewer than 300 individuals left in China, it is necessary to conserve the Pudong White pig and conduct selective breeding for disease resistance. Studying polymorphisms in FUT1 and TAP1, which are resistant to ETEC F18 in the Pudong White pig, is important for breeding disease resistance and protecting our rich genetic resources in Chinese native breeds. If genotypes of disease resistance are identified, it will provide the ideal genetic resources. Measuring immune indices and conducting comparative analysis with Large White pigs will help us evaluate immune performance of Pudong White pigs more fully and provide useful information for further functional studies. The aforementioned acquired information can facilitate us to develop subsequent studies of disease resistance and breeding, and enable us to investigate the relationship between immune or economic characters and FUT1 and TAP1 genotypes in this endemic breed.

\section{MATERIAL AND METHODS}

\section{Samples and DNA isolation}

Animals used in this experiment were from the Shanghai Pudong Pig Breeding Farm (Pudong, Shanghai, China). A total of 342 pure healthy individuals, 8 to 12 weeks old, were examined, including Large White $(N=174)$ and Pudong White $(N=168)$ pigs. All samples were under the same forage and feeding management conditions and disease control in accordance with the Guide for Chinese Feeding Standard of Swine. Genomic DNA was extracted from blood using standard methods (Sambrook et al., 1989) and the DNA concentration of samples was measured using a spectrophotometer (at 260 and $280 \mathrm{~nm}$ absorbance).

\section{Polymerase chain reaction-Restriction fragment length polymorphism (PCR-RFLP) analysis}

FUT1 sequences (421 bp) were obtained using PCR with locus-specific primer pairs. The primer pair used for FUT1 (Vogeli et al., 1997) amplification was F: 5'-CTTCCTGAACGTCATCAAGACC-3' and R: 5'-CTTCAGCCAGGGCTCCTTTAAG-3' (Sangon, Shanghai, China). The primer pair for TAP1 exon 3 (Sun et al., 2012; Zhao et al., 2014) was F: 5'-GAAATGTGGATAAGAGCA-3' and R: 5'-AAACAGACGGATAATGAAAGAGG-3' (Sangon). Amplification reactions were carried out on 80 to $150 \mathrm{ng}$ genomic DNA in a $50 \mu \mathrm{L}$ reaction volume containing $48 \mu \mathrm{L}$ compound pfu PCR buffer (final concentration $1 \mathrm{X}$ buffer, $2 \mathrm{mM} \mathrm{MgCl}_{2}, 10 \mathrm{mM}$ each dNTP, $25 \mu \mathrm{M}$ each primer, and $5 \mathrm{U}$ pfu polymerase; TaKaRa, Dalian, China). PCR conditions included an initial denaturing step at $94^{\circ} \mathrm{C}$ for $4 \mathrm{~min}$, followed by 30 cycles of a three-step process of denaturing at $95^{\circ} \mathrm{C}$ for $30 \mathrm{~s}, 55^{\circ} \mathrm{C}\left(\right.$ FUT1) and $46^{\circ} \mathrm{C}\left(\right.$ TAP1) for $50 \mathrm{~s}$, and extension at $72^{\circ} \mathrm{C}$ for 1 min, followed by a final extension at $72^{\circ} \mathrm{C}$ for $10 \mathrm{~min}$.

Based on the PCR products, PCR-RFLP analysis was performed using the specific restriction enzymes Hhal for FUT1 and Mbol for TAP1 (TaKaRa) followed by electrophoresis on $8 \%$ polyacrylamide gels and detection using the silver-staining method (Sambrook et al., 1989). After purifying DNA using the MiniBEST DNA Fragment Purification kit Ver.4.0 (TaKaRa), the amplified DNA $(17 \mu \mathrm{L})$ was digested at $37^{\circ} \mathrm{C}$ with $1 \mathrm{U}$ of $\mathrm{Hhal}$ for $2 \mathrm{~h}$ and $1 \mathrm{U}$ of $\mathrm{Mbol}$ for $4 \mathrm{~h}$. The digested fragments were electrophoresed on $2 \%$ agarose gels in $1 \mathrm{X}$ TAE at a constant voltage of $120 \mathrm{~V}$ for $25 \mathrm{~min}$ and visualized under ultraviolet light. 


\section{Sequencing}

PCR products of FUT1 and TAP1 from the pigs were purified. After combining with A-Tailing (TaKaRa NDAA-Tailing kit), the products were ligated into a PMD-18T vector, and transformed into E. coli DH5a-competent cells. After blue/white selection, a number of positive clones were selected and grown on a small scale. Five positive colonies selected from each product were checked by electrophoresis on a $1.5 \%$ agarose gel and additional colonies were analyzed if necessary. Plasmid DNA was isolated and the samples were sequenced by Sangon Biotech (Shanghai, China) in both directions directly.

\section{Measurement of immune indices}

Indices of a mammals' immunity, interleukin-6 (IL-6), interleukin-10 (IL-10), and tumor necrosis factor alpha (TNF-a), were measured using ELISA kits (Yuanye, Shanghai, China) in Pudong White and Large White pigs with different genotypes at the FUT1 and TAP1 genes.

\section{Data analysis}

All obtained sequences were compared with the submitted sequences of Sus scrofa in GenBank (accession No. BX323833 for FUT1 and AK396698 for TAP1). All sequences were aligned using Clustal $X$ (Thompson et al., 1997) with the default settings and refined manually. Allele and genotype frequencies were calculated according to the Hardy-Weinberg equilibrium (HWE), which is the difference between the predicted value and the detected value:

$$
\begin{array}{ll}
\mathrm{p}=\mathrm{P}+\mathrm{H} / 2 & (\text { Equation 1) } \\
\mathrm{q}=\mathrm{Q}+\mathrm{H} / 2 & \text { (Equation 2) } \\
\mathrm{x}^{2}=\sum \mathrm{d}^{2} / \mathrm{e} & \text { (Equation 3) } \\
\mathrm{d}=\mathrm{e}-\mathrm{o} \mathrm{d}^{2} / \mathrm{e} & \text { (Equation 4) }
\end{array}
$$

where, $p$ and $q$ represent allele frequencies at certain positions. A general linear model (GLM) was established to analyze the genotype effects of FUT1 on measured traits. The following linear model was used:

$$
\mathrm{y}_{\mathrm{ij}}=\mu+\mathrm{G}_{\mathrm{i}}+\mathrm{e}
$$


where, $\mathrm{y}_{\mathrm{ij}}$ represents the measured traits, $\mu$ the overall mean, $\mathrm{G}_{\mathrm{i}}$ the genotype effect of FUT1 or TAP1 gene, and e is the residual error. These statistical analyses were carried out using the SPSS 16.0 software.

\section{RESULTS}

\section{Analysis of PCR-RFLP and sequencing results}

PCR products were detected using $1 \%$ agarose electrophoresis. Two clear, specific DNA bands were observed at 421 and $767 \mathrm{bp}$, which agreed with the predicted amplified fragment sizes of FUT1 and TAP1, respectively.

There are two restriction recognition sites for Hha I, one at position M307 and the other is a fixed enzyme loci in the FUT1 gene, which can be completely digested by Hha I to produce the GG phenotype (241/93/87 bp). If this position has a G/A mutation, the Hha I enzyme would not be able to digest the position of M307, resulting in an AA genotype (328/93 bp). If two alleles exist at the M307 position, it produces an AG genotype (328/241/93/87 bp). The restriction map is shown in Figure 1A.

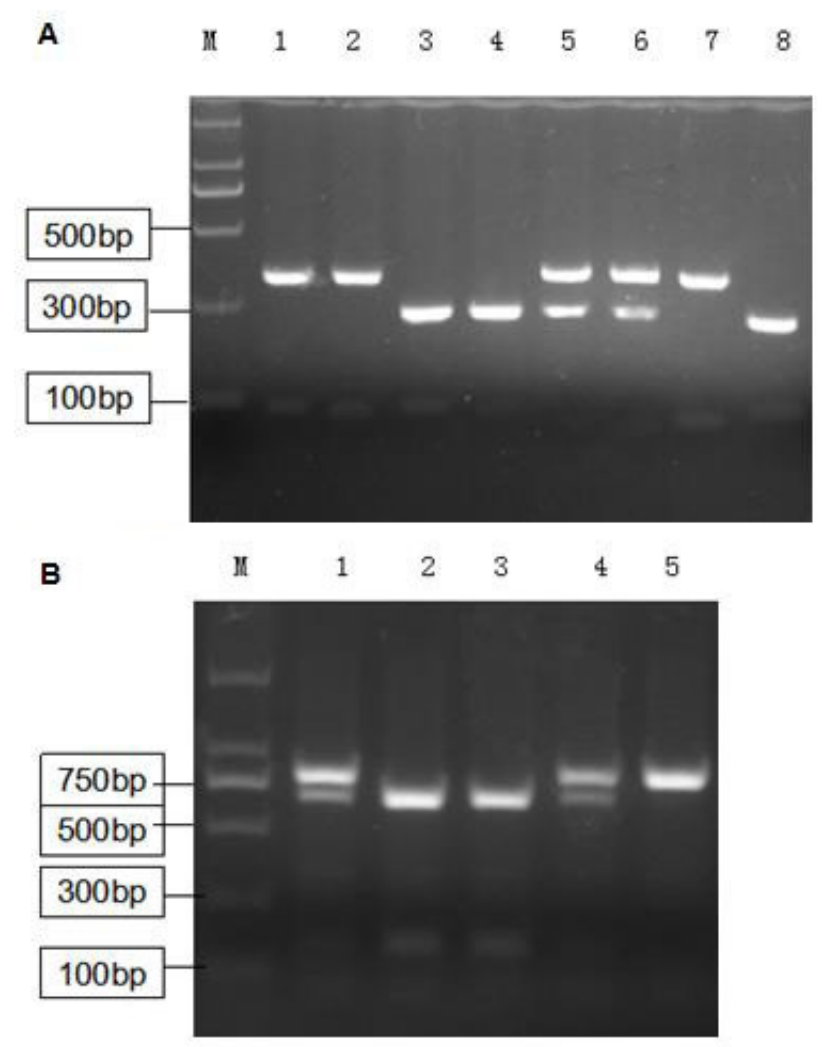

Figure 1. Genotyping results of the FUT1 gene (A) and the TAP1 gene (B) in pigs based on polymerase chain reactionrestriction fragment length polymorphism analysis (PCR-RFLP). Lane $M=$ DL2000 marker. A. Lanes 1, 2, and $7=$ genotype AA; lanes 3, 4, and 8 = genotype GG; lanes 5 and $6=$ genotype AG. B. Lane 5 = genotype AA; lanes 2 and 3 = genotype GG; lanes 1 and 4 = genotype AG. 
There is only one restriction recognition site at position G729 in the TAP1 gene for Mbol, which can be completely digested by Mbo I to produce the GG phenotype (628/139 bp). If this position has a G/A mutation, the Mbo I enzyme would not be able to digest the G729 position, resulting in an AA genotype (767 bp). If two alleles exist at the $G 729$ position, it produces an AG genotype (767/628/139 bp). The restriction map is shown in Figure $1 \mathrm{~B}$.

\section{Polymorphism of FUT1 in Pudong White and Large White pigs}

Among the 174 samples for Large White pigs, the number of AA, AG, and GG genotypes at the FUT1 gene were 9, 78, and 87, respectively. Their corresponding genotype frequencies were $0.052,0.448$, and 0.500 , respectively. The frequency for the disease resistant allele $A$ was 0.276 , while the frequency for the sensitive allele $G$ was 0.724 (Table 1). The number of AA, AG, and GG genotypes at FUT1 in the 168 Pudong White pigs was 3, 68, and 97, respectively. Their corresponding genotype frequencies were $0.018,0.405$, and 0.577 , respectively. The frequency for the disease resistant allele A was 0.220, while the frequency for the sensitive allele $\mathrm{G}$ was 0.780 . The AA genotype, which confers disease resistance in Pudong White pigs, was less common in Pudong White pigs than in Large White pigs $(P<0.05)$.

Table 1. Genotype and allele frequencies of the FUT1 gene from Large White and Pudong White pigs in China.

\begin{tabular}{|c|c|c|c|c|c|c|c|}
\hline \multirow[t]{2}{*}{ Breed } & \multirow[t]{2}{*}{ Number } & \multicolumn{3}{|c|}{ Genotype } & \multicolumn{2}{|c|}{ Allele } & \multirow[t]{2}{*}{ Chi-square value } \\
\hline & & GG & $A G$ & AA & G & A & \\
\hline Large white & 174 & $0.500(87)$ & $0.448(78)$ & $0.052(9)$ & 0.724 & 0.276 & 6.62 \\
\hline Pudong white & 168 & $0.577(97)$ & $0.405(68)$ & $0.018(3)$ & 0.780 & 0.220 & 7.54 \\
\hline
\end{tabular}

Figures in brackets are number of samples; Chi-square value denotes Hardy-Weinberg equilibrium test values for different genotypes; Chi-square ${ }_{0.05}(2)=5.991 ; P<0.05$. $^{2}$

As shown in Table 2, among the 174 Large White pig samples, three genotypes were present. Statistical analysis for PCR-RFLP genotypes and their frequencies in the Large White pig TAP1 gene indicated that the frequencies of AA, AG, and GG genotypes were 0.029, 0.276, and 0.695 , respectively. The frequency for the sensitive allele A was 0.167 and the TAP1 exon 3 $G$ allele is the predominant allele with a frequency 0.833 . For Pudong White pigs, the number of $A A, A G$, and $G G$ genotypes was 21,28 , and 119 , respectively. The frequencies of $A A, A G$, and $G G$ genotypes were $0.125,0.167$, and 0.708 , respectively. The frequency for the sensitive allele $A$ was 0.208 , and for the $G$ allele was 0.792 . There was no significant difference in the frequency of the GG genotype (confers disease resistance) between the two pig breeds $(P>0.05)$.

\begin{tabular}{|c|c|c|c|c|c|c|c|}
\hline \multirow[t]{2}{*}{ Breed } & \multirow[t]{2}{*}{ Number } & \multicolumn{3}{|c|}{ Genotype } & \multicolumn{2}{|l|}{ Allele } & \multirow[t]{2}{*}{ Chi-square value } \\
\hline & & GG & $A G$ & AA & G & A & \\
\hline Large White & 174 & $0.695(121)$ & $0.276(48)$ & $0.029(5)$ & 0.833 & 0.167 & 30.39 \\
\hline Pudong White & 168 & $0.708(119)$ & $0.167(28)$ & $0.125(21)$ & 0.792 & 0.208 & 43.82 \\
\hline
\end{tabular}

Figures in brackets are number of samples; Chi-square value denotes Hardy-Weinberg equilibrium test values for different genotypes; Chi-square $0.05(2)=5.991 ; P<0.05$. 


\section{Immune performance analysis}

The results of the least square method for the three genotypes of the FUT1 gene and the immune indices are shown in Table 3. No significant differences were observed in IL-6 and IL-10 levels among the different genotypes in Pudong White and Large White pigs ( $P>0.05)$. TNF- $\alpha$ levels were significantly higher in AA genotype individuals compared to individuals with the $G G$ and $A G$ genotypes, in both pig breeds $(P<0.05)$. There were no significant differences in TNF- $\alpha$ levels between $G G$ and $A G$ genotypes.

Table 3. Association of FUT1 M307 polymorphisms with immune indices in Pudong White and Large White pigs.

\begin{tabular}{|c|c|c|c|c|c|c|}
\hline \multirow{2}{*}{$\begin{array}{l}\text { Breed } \\
\text { Genotype }\end{array}$} & \multicolumn{3}{|c|}{ Pudong White pig } & \multicolumn{3}{|c|}{ Large White pig } \\
\hline & AA & $A G$ & GG & AA & $A G$ & GG \\
\hline IL-6 & $60.50 \pm 2.55$ & $58.47 \pm 7.04$ & $62.58 \pm 2.83$ & $62.67 \pm 4.25$ & $57.49 \pm 3.04$ & $61.35 \pm 3.59$ \\
\hline IL-10 & $12.56 \pm 1.29$ & $14.72 \pm 3.16$ & $15.35 \pm 2.42$ & $14.68 \pm 1.49$ & $15.43 \pm 2.24$ & $16.04 \pm 1.53$ \\
\hline TNF- $\alpha$ & $16.32 \pm 2.57^{\mathrm{a}}$ & $14.71 \pm 1.81^{\mathrm{b}}$ & $14.58 \pm 2.03^{\mathrm{bc}}$ & $17.37 \pm 2.03^{e}$ & $15.94 \pm 1.48^{f}$ & $16.03 \pm 2.25^{\mathrm{fg}}$ \\
\hline
\end{tabular}

Different superscript letters in the same column denote significant differences $(P<0.05)$; the same letter or no letter denotes no significant difference $(P>0.05)$. Units are $\mathrm{pg} / \mathrm{mL}$.

The results of the least square method for the three genotypes of the TAP1 gene in Table 4 showed that there were no significant differences in IL-6 and IL-10 levels among the different genotypes in both pig breeds $(P>0.05)$. However, TNF-a levels were higher in individuals with the GG genotype compared to those with the AG and AA genotypes, in both pig breeds $(P<0.05)$.

Table 4. Association of TAP1 M729 polymorphisms with immune indices in Pudong white and Large White pigs.

\begin{tabular}{|c|c|c|c|c|c|c|}
\hline \multirow{2}{*}{$\begin{array}{l}\text { Breed } \\
\text { Genotype }\end{array}$} & \multicolumn{3}{|c|}{ Pudong White pig } & \multicolumn{3}{|c|}{ Large White pig } \\
\hline & GG & $A G$ & AA & GG & $A G$ & AA \\
\hline IL-6 & $65.57 \pm 2.45$ & $58.45 \pm 3.41$ & $56.704 \pm 1.13$ & $71.48 \pm 8.01$ & $65.52 \pm 3.01$ & $67.79 \pm 3.61$ \\
\hline IL-10 & $20.70 \pm 0.73$ & $18.49 \pm 0.50$ & $18.27 \pm 1.00$ & $13.74 \pm 1.82$ & $14.58 \pm 0.61$ & $14.16 \pm 1.10$ \\
\hline TNF- $\alpha$ & $17.87 \pm 0.35^{a}$ & $15.99 \pm 0.30^{b}$ & $15.83 \pm 0.24^{\mathrm{bc}}$ & $17.67 \pm 0.12^{\mathrm{a}}$ & $16.24 \pm 0.13^{b}$ & $16.15 \pm 0.15^{\mathrm{bc}}$ \\
\hline
\end{tabular}

Different superscript letters in the same column denote significant differences $(P<0.05)$; the same letter or no letter denotes no significant difference $(P>0.05)$. Units are $\mathrm{pg} / \mathrm{mL}$.

\section{DISCUSSION}

\section{Polymorphism of the FUT1 gene}

The FUT1 gene on chromosome 6qll is a candidate gene thought to control adhesion to the F18 receptor (Vogeli et al., 1997). Research by Meijerink et al. (1997) has shown the existence of a G/A mutation at nucleotide 307 of the FUT1 open reading frame (ORF). Pigs with the AA genotype are resistant to ETEC F18 infection, whereas pigs with the GG, or heterozygote AG, genotype are sensitive to ETEC F18 infection (Meijerink et al., 1997). Previous studies investigating polymorphisms at nucleotide 307 of FUT1 in Chinese native pig breeds and imported breeds discovered that the AA genotype (confers resistance to F18 infection) was not present in any Chinese native breeds, it only occurred in imported strains (Meijerink et al., 1997; Shi et al., 2003; Bao et al., 2008). Furthermore, all Chinese pig breeds have the GG genotype, except the 
Lingao breed, which carries the AG genotype (Bao et al., 2008). Many Chinese scientists have discovered an extremely skewed distribution in Chinese domestic pig breeds (Shi et al., 2002). However, polymorphism analysis of FUT1 and immune traits analysis have rarely been conducted until recently. Kim et al. (2013) found that piglet survival of individuals with the AA genotype was almost two-fold greater than GG individuals. The FUT1 polymorphism can be used as an effective marker for selection programs to improve post-weaning piglet survival. Luo et al. (2010) discovered that FUT1 M307 genotypes were very strongly associated with the F18ac adhesion phenotypes, drawing the conclusion that the polymorphism at FUT1 M307 can be used for marker-assisted selection of porcine PWD and ED resistant pigs. Zhu et al. (2014) studied FUT1 M307 and immune indices in Yorkshire pigs and the results showed that there were no significant differences among the three genotypes in terms of IL-6 and IL-10 levels $(P>0.05)$.

In our research, following polymorphism analysis of FUT1 M307 in Large White pigs, three genotypes were observed with the frequency $G G>A G>A A$. Our results are consistent with those from a study of Western pig breeds, where the polymorphism was observed to have low frequencies of the disease resistant genotype AA (Meijerink et al., 1997; Bao et al., 2008). After analyzing the FUT1 M307A polymorphism in Pudong White pigs, the disease resistant genotype AA (0.018), which has not been found in any other Chinese domestic pig breeds, was found in this breed for the first time, implying that Pudong White pigs have a genetic background with advantages in resisting F18 infection compared with many other Chinese native pig breeds. The AG (0.405) genotype, previously only observed in the Lingao breed (Bao et al., 2008), was also detected in Pudong White pigs. The results of the current study are inconsistent with reports that Chinese local pig breeds and wild pigs lack the AA genotype that provides resistance to ECF18 bacteria (Meijerink et al., 1997; Shi et al., 2002; Wu et al., 2006; Bao et al., 2008). Chi-square fitness analysis showed that FUT1 M307 deviated from HWE in both pig breeds, which means that this locus does not have stable and constant heredity in Pudong White and Large White pigs in China. This result is in agreement with Shi et al. (2002), who state that many Chinese scientists have discovered an extremely skewed distribution in Chinese domestic pig breeds.

\section{Polymorphism of the TAP1 gene}

At present, some researchers have reported that TAP1 may be an effective anti-E. coli F18 molecular marker in pigs, and it is also correlated with virus infection (Ambagala et al., 2000, 2003; Chen and Wu, 2009). Using real-time PCR, Sun et al. (2012) found that TAP1 had high expression levels in immune tissues. TAP1 plays a significant role in immune responses because of its increased expression level after infection by viruses and bacteria. Zhao et al. (2014) analyzed TAP1 mRNA relative expression levels in 11 tissues from resistant and susceptible phenotypes, and found that the G729A mutation of TAP1 had a significant effect on TAP1 mRNA expression, with high expression possibly conferring resistance against $E$. coli $\mathrm{F} 18$, which confirms that the TAP1 gene plays an important role in E. coli F18 resistance (Wang et al., 2014). These results are also in agreement with Bao et al. (2012).

The Pudong White pig is supported as a new Chinese local breed. Following analysis of polymorphism G729 in TAP1 in Pudong White pigs, we discovered the presence of the GG genotype (0.708), where $G$ is the dominant allele $(0.792)$, and the frequency of $G G$ in Large White pigs was 0.695. Chi-square fitness analysis showed that this locus deviated from HWE in both Pudong White pigs and Large White pigs $(P<0.05)$. This may be affected by the general disease 
resistance or selective pressures, such as natural selection acting on silent changes in DNA, or both mutational biases and natural selection (Duret and Mouchiroud, 1999; Grocock and Sharp, 2002).

\section{Immune performance analysis}

As immune parameters may represent the body's immune function and, thus, indirectly reflect the disease resistance of the body, we measured immune indices in Pudong White pigs to analyze the immune performance of individuals with disease resistant genotypes. IL-6 is a classic well-known pro-inflammatory cytokine, which is secreted by the CD4+Th2 cell (helper T2 cell). It plays important roles in homeostatic mechanisms and enhances the hepatocyte inflammatory response. IL-10 is a classic anti-inflammatory cytokine, which displays immunosuppressive activities (Nishimoto and Kishimoto, 2006; Yao et al., 2014). IL-10 has also been reported to enhance B cell activation, proliferation, and differentiation into immunoglobulin (Ig) secreting cells (Itoh and Hirohata, 1995; Hilgenberg et al., 2014). Our results showed there were no significant differences in the levels of IL- 6 and IL-10 among the three genotypes in both Pudong White and Large White pigs $(P>0.05)$ for both the FUT1 and TAP1 gene, which suggests that Pudong White pigs have the same ability to enhance the hepatocyte inflammatory response and the same ability of B cell activation, proliferation, and differentiation as Large White pigs. Obviously, the two immune responses above have a certain degree of influence on the Pudong White pig's immune ability to resist F18 infection or other infections, which illustrates the reasons why Pudong White piglets have better ED and PWD disease resistance than many other Chinese native breeds. A similar phenomenon was reported in Zhu et al. (2014).

TNF- $\alpha$ secreted by CD4+Th1 cells (helper T1 cell), as a member of the TNF superfamily, can prompt apoptosis, and prevent tumorigenesis, virus replication, and the proliferation of pathogens, and is an essential cytokine to maintain internal stability and resist pathogenic factors (Tracey et al., 1990). Our study discovered that TNF- $\alpha$ levels were higher in individuals with the GG genotype (resistant to F18 infection) at the TAP1 gene compared to individuals with the AG and GG genotypes in both Pudong White and Large White pigs $(P<0.05)$, which demonstrates that among the three genotypes, the immuno-regulation ability of GG genotype (resistant to F18 infection) individuals may be stronger. Meanwhile, there was no significant difference in TNF- $\alpha$ levels between individuals with the GG genotype at TAP1 (resistant to F18 infection) in Pudong White pigs and Large White pigs. TNF- $\alpha$ levels in individuals with the AA genotype at FUT1 (resistant to F18 infection) were higher than in individuals with the AG and GG genotypes in both Pudong White and Large White pigs $(P<0.05)$, which demonstrates that among the three genotypes, the immuno-regulation ability of AA genotype (resistant to F18 infection) individuals may be stronger. However, TNF- $\alpha$ levels were higher in individuals with the disease resistant AA genotype at FUT1 in Large White pigs compared to Pudong White pigs $(P<0.05)$, which means Large White pigs may have stronger anti-virus and immuno-regulation ability to resist infection compared to Pudong White pigs. However, because the AA genotype (resistant to F18 infection) was discovered in Pudong White pigs, the results imply that Pudong White pigs have a genetic background with advantages in resisting F18 infection compared with many other Chinese native pig breeds.

Individuals with a genotype that resists F18 infection at both the FUT1 and TAP1 genes have better immuno-regulation ability than the other two genotypes that do not confer ability to resist F18. Based on the results above, we can infer that the AA genotype of FUT1 and the GG genotype of TAP1 may be associated with TNF- $\alpha$ levels; however, we need to verify this conclusion by expanding the study to sample a greater number of Pudong White Pigs. 
In conclusion, we identified the AA genotype of the FUT1 gene and the GG genotype of the TAP1 gene, which confer a stronger ability to resist $E$. coli F18 infection, in Pudong White pigs. These results imply that Pudong White pigs have a genetic background with advantages in resisting F18 infection compared with many other Chinese native pig breeds. The immune indices showed that Large White pigs may have stronger immuno-regulation ability than Pudong White pigs, particularly in regards to TNF- $\alpha$, but the two breeds may have the same ability to enhance the hepatocyte inflammatory response and the same ability of B cell differentiation, based on IL-6 and IL-10 levels. These results can facilitate development of subsequent studies of disease resistance and selective breeding, and also enable investigations of the relationships between other economic and immune characters and FUT1 and TAP1 genotypes of this endemic breed.

\section{Conflicts of interest}

The authors declare no conflict of interest.

\section{ACKNOWLEDGMENTS}

We thank farm staff who helped to collect all the related data. Research supported by the project "Study and setting an example of key technology for protection and development of genetic resources of Shanghai Local pig breeds", supported by the Shanghai development of Seed Industry [Hu nong ke (2012) No. 5] and the project of Shanghai Industrial Technology System of Pig Modern Agriculture.

\section{REFERENCES}

Ambagala AP, Hinkley S and Srikumaran S (2000). An early pseudorabies virus protein down regulates porcine MHC class I expression by inhibition of transporter associated with antigen processing (TAP). J. Immunol. 164: 93-99.

Ambagala AP, Gopinath RS and Srikumaran S (2003). Inhibition of TAP by pseudorabies virus is independent of its vhs activity. Virus Res. 96: 37-48.

Bao WB, Wu SL, Musa HH, Zhu GQ, et al. (2008). Genetic variation at the alpha-1-fucosyltransferase (FUT1) gene in Asian wild boar and Chinese and Western commercial pig breeds. J. Anim. Breed. Genet. 125: 427-430.

Bao WB, Ye L, Zi C, Su XM, et al. (2012). Study on the age-dependent tissue expression of FUT1 gene in porcine and its relationship to E. coli $\mathrm{F} 18$ receptor. Gene 497: 336-339.

Benin AM and Duchet-Suchaux MF (1991). Relationship between virulence and adherence of various enterotoxigenic Escherichia coli: strains to isolated intestinal epithelial cells from Chinese Meishan and European Large White pigs. Am. J. Vet. Res. 52: 45-49.

Chen HY and WU ZF (2009). Prospective of BF, DRB, DQB, TAP1 and IFN- $\gamma$ genes used as porcine marker assisted disease resistance and breeding. Biotechnol. Bull. 1: 103-106.

Cresswell P, Bangia N, Dick T and Diedrich G (1999). The nature of the MHC class I peptide loading complex. Immunol. Rev. 172: $21-28$.

Duret $L$ and Mouchiroud D (1999). Expression pattern and, surprisingly, gene length shape codon usage in Caenorhabditis, Drosophila, and Arabidopsis. Proc. Natl. Acad. Sci. U. S. A. 96: 4482-4487.

Grocock RJ and Sharp PM (2002). Synonymous codon usage in Pseudomonas aeruginosa PA01. Gene 289: 131-139.

Hilgenberg E, Shen P, Dang VD, Ries S, et al. (2014). Interleukin-10-producing B cells and the regulation of immunity. Curr Top. Microbiol. Immunol. 380: 69-92.

Imberechts H, De Greve H, Schlicker C, Bouchet H, et al. (1992). Characterization of F107 fimbriae of Escherichia coli 107/86, which causes oedema disease in pigs and nucleotide sequence of F107 major fimbrial subunit gene, fedA. Infect. Immun. 60: 1963-1971.

Itoh K and Hirohata S (1995). The role of IL-10 in human B cell activation, proliferation, and differentiation. J. Immunol. 154: 4341-4350. 
Kim K, Nguyen DT, Choi M, Kim JH, et al. (2013). Alpha (1,2)-fucosyltransferase M307A polymorphism improves piglet survival. Anim. Biotechnol. 24: 243-250.

Luo Y, Qiu XT, Li HJ and Zhang Q (2010). Association between the polymorphism in FUT1 gene and the resistance to PWD and ED in three pig breeds. Asian Australas. J. Anim. Sci. 23: 1268-1275.

Meijerink E, Fries R, Vogeli P, Masabanda J, et al. (1997). Two alpha(1,2) fucosyltransferase genes on porcine chromosome 6q11 are closely linked to the blood group inhibitor (S) and Escherichia coli F18 receptor (ECF18R) loci. Mamm. Genome 8: 736-741.

Nagy B and Fekete PZ (1999). Enterotoxigenic Escherichia coli (ETEC) in farm animals. Vet. Res. 30: 259-284.

Nishimoto N and Kishimoto T (2006). Interleukin 6: from bench to bedside. Nat. Clin. Pract. Rheumatol. 2: 619-626.

Ouyang KX, Wang LX and Lin CJ (2004). The advance in the relationship between immunity indexes, disease resistance and production traits. China Anim. Vet. Mes. 31: 23-25.

Parcej D and Tampe R (2010). ABC proteins in antigen translocation and viral inhibition. Nat. Chem. Biol. 6: 572-580.

Rozas J, Sanchez-Delbarris JC, Messeguer X and Rozas R (2003). DnaSP, DNA polymorphism analyses by the coalescent and other methods. Bioinformatics 19: 2496-2497.

Sambrook J, Fritsch EF and Maniatis T (1989). Molecular cloning: a laboratory manual 2nd edn. Cold Spring Harbor Laboratory Press, New York.

Shi QS, Huang SQ, Liu XC, He CQ, et al. (2003). Polymorphism of E. coli F18 receptor gene in different pig breeds. Acta Genet. Sin. 30:221-224.

Sun N, Liu D, Chen H, Liu X, et al. (2012). Localization, expression change in PRRSV infection and association analysis of the porcine TAP1 gene. Int. J. Biol. Sci. 8: 49-58.

Thompson JD, Gibson TJ, Plewniak F, Jeanmougin F, et al. (1997). The Clustal_X windows interface: flexible strategies for multiple alignment aided by quality analysis tools. Nucleic Acids. Res. 25: 4876-4882.

Tracey KJ, Lane F and Hilkens CM (1990). Introduction of tolerance by TNF-treated dendritic cells. Lancet 8648: 1721-1728.

Vogeli P, Meijerink E, Fries R, Neuenschwander S, et al. (1997). A molecular test for the detection of E. coli F18 receptors: a breakthrough in the struggle against oedema and post-weaning diarrhoea in swine. Schweiz. Arch. Tierheilkd. 139: 479-484.

Wang J, Liu Y, Dong WH, Huo YJ, et al. (2014). Dynamic changes in TAP1 expression levels in newborn to weaning piglets, and its association with Escherichia coli F18 resistance. Genet. Mol. Res. 13: 3686-3692.

Wu SL, Ju HP, Bao WB, Chen GH, et al. (2006). Detection of point mutation of porcine alpha1 fucosyltransferase gene by PCR-SSCP approach. J. YZU Agr. Lif. Sci. Edi. 27: 68-71.

Yao X, Huang J, Zhong H, Shen N, et al. (2014). Targeting interleukin-6 in inflammatory autoimmune diseases and cancers. Pharmacol. Ther. 141: 125-139.

Zhao Q, Liu Y, Dong W, Zhu S, et al. (2014). Genetic variations of TAP1 gene exon3 affects gene expression and Escherichia coli F18 resistance in piglets. Int. J. Mol. Sci. 15: 11161-11171.

Zhu SP, Liu Y, Dong WH, Zheng XR, et al. (2014). Polymorphism of FUT1 gene M307 and its relationship with partial immune indexes and economic traits in Yorkshire pigs. Asian J. Anim. Vet. Adv. 9: 253-261. 